\title{
Let us complete the puzzle together: a jigsaw cooperative learning trial on optical graduate course
}

Ya Zhou, Yao Hu, Shanshan Wang, Yuejin Zhao, Liquan Dong, et al.

Ya Zhou, Yao Hu, Shanshan Wang, Yuejin Zhao, Liquan Dong, Yong Song, "Let us complete the puzzle together: a jigsaw cooperative learning trial on optical graduate course," Proc. SPIE 11143, Fifteenth Conference on Education and Training in Optics and Photonics: ETOP 2019, 111432J (2 July 2019); doi: 10.1117/12.2523386 


\title{
Let us complete the puzzle together: A Jigsaw Cooperative Learning Trial on Optical Graduate Course
}

\author{
Ya Zhou*, Yao Hu, Shanshan Wang, Yuejin Zhao, Liquan Dong, Yong Song \\ Beijing Key Lab. for Precision Optoelectronic Measurement Instrument and Technology, \\ School of Optics and Photonics, Beijing Institute of Technology, Beijing 100081, China
}

\begin{abstract}
Traditional lectures do hardly satisfy or benefit all of graduate students because of their diversity background, which might lead to inactive in the class, especially when the courses are professionally concentrated. Jigsaw cooperative learning (JCL), a student-centered learning method which engages all students and is beneficial in facilitating relationship-building, might be an alternative solution. A trial was made in an optical course "Optical Interferometric Measurement (OIM)". However, the first trial we made is hardly counted as success. After thorough analysis on all factors that might cause the frustration, a new course plan is formed detailed. In this paper, we would like share our trials made in the course, both the unsuccessful one and the one work in progress.
\end{abstract}

Keywords: Jigsaw cooperative learning; Student-centered learning; Graduate course

\section{INTRODUCTION}

The most challenging part of preparing courses for graduate students might be the diversity background of the students. After at least four years' undergraduate study, the graduate students have already formed their own study or think mode which definitely differ in thousands of ways since they are from different universities and different majors. Traditional lectures do hardly satisfy or benefit all of them, which might lead to inactive in the class, especially when the courses are professionally concentrated.

Optical Interferometric Measurement (OIM) is a graduate course offering to the students majored in Instrumentation Science and Technology, Optical Engineering, Physical Electronics, and other engineering specialties in Beijing Institute of Technology, which demands many optical prerequisites such as Applied Optics, Physical Optics, Error Theory and Data Procession, and etc. However, less than $40 \%$ of the graduate students registered in the course have ever had all the prerequisite courses, and what make it worse is that this course is supposed to be given in English although its original intension is to help the graduate students to learn their specialty with international perspective. Both the lack of necessary basic knowledge and the language barrier cumbered the students' learning progress in traditional lectures. Naturally it flashed in our mind that cooperative learning ${ }^{1-3}$ method which engages all students and is beneficial in facilitating relationship-building, might be an alternative solution.

Jigsaw cooperative learning (JCL $)^{4}$, a student-centered learning method was introduced in the first run of OIM teaching, based on the belief that the diverse study or think mode of each member, which is a negative drag in traditional lecture learning, can play a positive role in this procedure. Base on some investigations on the Jigsaw II method and Reverse Jigsaw method, along with several experiences on pedagogy of Learning by Teaching ${ }^{5}$, we designed the course plan for a class of more than fifty students. In the OIM class, the students were grouped as four teams while four typical interferometric measurement technology were chosen and assigned to them one by one. Each interferometric measurement technology includes several key contents and each member of a group was assigned a "piece" of the puzzle (content). They were expected to research and consult with members till they get a full understanding about their puzzle piece and begin to be curious about the whole picture. We suppose they would learn from each other further developing their knowledge. Reporting back to their group and the whole class, they would teach their "piece" of the puzzle to their classmates. Then, they could complete the puzzle together.

*zhouya@bit.edu.cn;

Fifteenth Conference on Education and Training in Optics and Photonics: ETOP 2019, edited by

Anne-Sophie Poulin-Girard, Joseph A. Shaw, Proc. of SPIE Vol. 11143, 111432J · (C) 2019

SPIE, ICO, IEEE, OSA · CCC code: 0277-786X/19/\$18 · doi: 10.1117/12.2523386 
However, the first trial we made was hardly counted as success. Although at the end of the semester the test scores and course grades turned to be OK, which indicated that the knowledge had been surely delivered as it should be, the participation and engagement of the students were not active enough as we assumed. According to the survey conducted after the course, only half students felt the pedagogy helpful to their learning and we even don't know if those students are just trying to be nice.

But as we constantly told our students, failure can always be a good lesson. What cannot defeat us will make us stronger. After thorough analysis on all factors that might cause the frustration, a new course plan is formed detailed. In this paper, we would like share our trials made in the course "Optical Interferometric Measurement", both the unsuccessful one and the one work in progress.

\section{THE COURSE: OPTICAL INTERFEROMETRIC MEASUREMENT}

Optical Interferometric Measurement (OIM) is a graduate course offered in School of Optics and Photonics, Beijing Institute of Technology. It is a traditional course, original in Chinese, offering to the graduate students majored in Instrumentation Science and Technology, Optical Engineering, Physical Electronics, and other engineering specialties, which aims to prepare the necessary knowledge of optical interference theory and its applications for those students whose research field is related to precision measurement.

This course introduces both basic and advanced optical approaches for the measurement of optical surfaces. Typical methods including different kinds of interferometers, and Hartmann testing, as well as related techniques such as Zernike polynomial based wavefront fitting are fully addressed. After completing this course, a student should be able to (1) select the correct method for the measured surface according to its roughness and shape; (2) master the basic principle of at least three kinds of methods; (3) do the systematic design and data processing of at least one kind of measurement system.

As any systematical graduate course which involves both theoretical knowledge and practical technique, the prerequisites of this course are critical and exigent, including: Physics, Applied Optics, Physical Optics, Experiment on Photoelectronic Imaging Principle and Technology, Error Theory and Data Procession. Because the students who registers in the course are usually from different schools and with diverse background, several lectures are designed as the review of those theories and principles that is extracted from the prerequisites and demanded for the following lectures. Most students find this course difficult because so many principles and theories are involved even with the review lectures (and even those lectures are given in Chinese).

With the development of internationalization of higher education, the course transferred to English version at 2018, the original intension of which is to introduce more latest researches in this field easily and help the graduate students to learn their specialty with international perspective. Unfortunately but not unexpectedly, the course became even more difficult to those students whose English skill is not so good. By those, I mean the majority of native students for whom English is their second language. Both the lack of necessary basic knowledge and the language barrier cumbered the students' learning progress in traditional lectures.

\section{THE DIVERSITY OF GRADUATE STUDENTS}

Recent decades, there was a growing consensus among the educators that the center of learning should transfer from teacher to student. Student-centered learning, also known as learner-centered education, broadly encompasses methods of teaching that shift the focus of instruction from the teacher to the student. This is in contrast to traditional education, also dubbed "teacher-centered learning", which situates the teacher as the primarily "active" role while students take a more "passive", receptive role. Can we help those students in OIM course by putting students at the center of the learning process? What kind of strategy would be desirable?

In order to find a better way to help the student to understand the knowledge involved in OIM as well as to improve their professional English skills, and furthermore, to help the introverted ones gain self-identity if possible, let us pay attention to our objects: the graduate students.

In China, national graduate entrance examination is one of the top challenge exams, the acceptance rate of which is as low as 20 percent and goes down every single year. The diversity of the accepted students appears in many ways, from their ages, their background to their work experience. After at least four years' undergraduate study, some of them with years or even decades of work experience, the graduate students have already formed their own study or think mode 
which definitely differ in thousands of ways since they are from different universities and different majors, with various work and life experience. Of course those learning mode are all efficient since they have made through the most challenging and tough graduate entrance examination with the help of them. On the other hand, their talents and their knowledge are limited in dissimilar particular fields because of their various backgrounds and experiences.

As consequence, it is challenging to select a particular teaching mode which can satisfy or benefit all of them, especially when the courses are professionally concentrated. As to the OIM course, which involves both theoretical knowledge and practical technique on Applied Optics, Physical Optics, Error Theory, and so on, the students are supposed to understand the theory of electromagnetic wave and the concept of interference to some certain degree before they enter the classroom, and necessary English skills and professional vocabulary as it's an English version course. However, the real situation is that many students had to choose this course because their upcoming research work demands. So the background of the registered students differed in a large scale even their research fields are related.

Professional Background
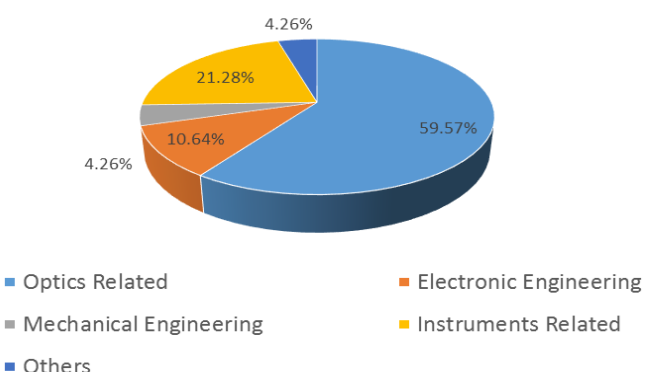

(a)

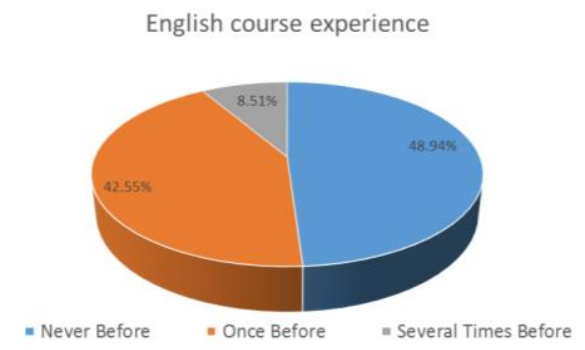

(b)

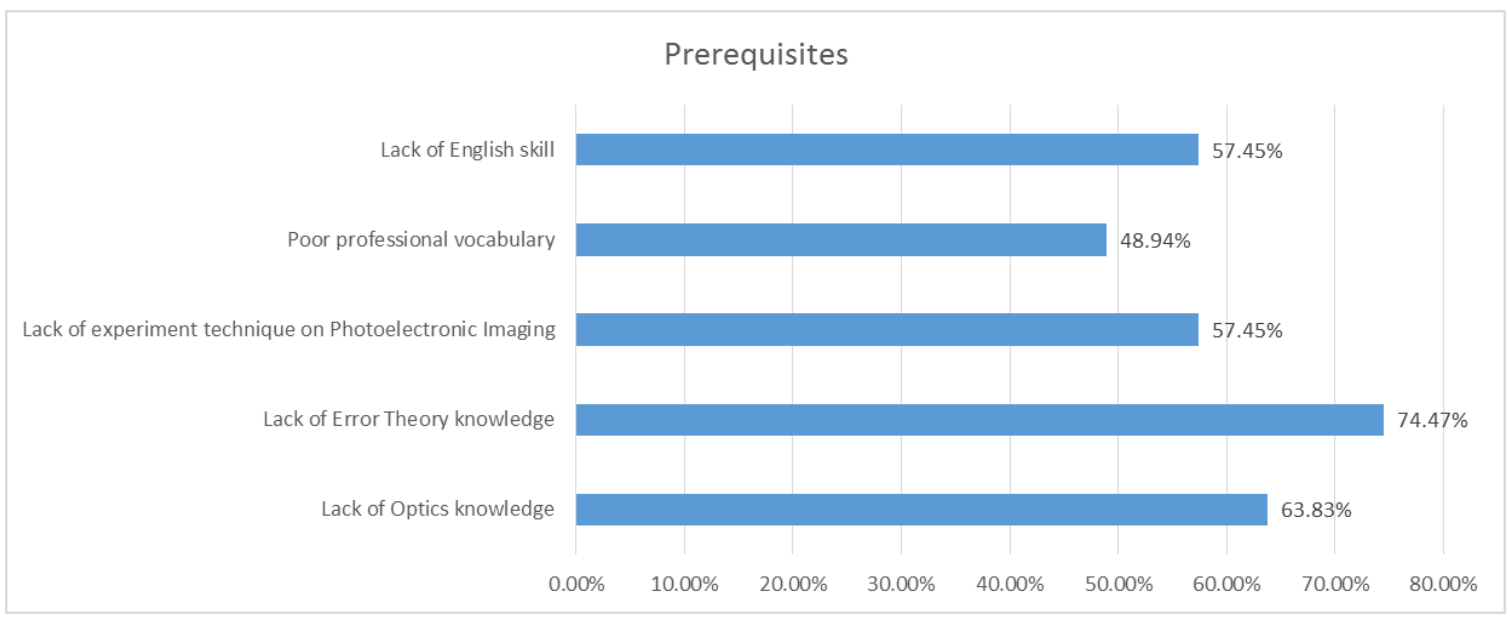

(c)

Figure 1. The Diversity of the graduate students in OIM. (a) Diversity in background; (b) Diversity in English course experience; (c) Diversity in prerequisites.

Let us take OIM as an example. Figure 1 shows the diversity of the students according to the survey conducted among the graduate students who had taken the OIM course in 2018. There were 53 students registered in the course who came from 4 different specialties 3 different schools of our university. Among 47 valid questionnaires, there were less than sixty percent of them had optics related professional background. Even among those who had had Physical Optics course during their college life, their understanding on the interference theory were at various level and in different perspective for they graduated from different university and every school would choose their material based on their own demand. More than forty percent of those student had never had any professional course in English, and only less than ten percent had had this kind of experience more than once. 


\section{AN UNSUCCESSFUL COOPERATIVE LEARNING TRIAL ON OIM}

It is logically to conclude that traditional lecture is not a perfect mode to use in a professionally concentrated course like OIM. Both the lack of necessary basic knowledge and the language barrier cumbered the students' learning progress in traditional lectures. Naturally it flashed in our mind that cooperative learning method which engages all students and is beneficial in facilitating relationship-building, might be an alternative solution.

Cooperative learning is the instructional use of small groups so that students work together to maximize their own and each other's learning, which in our opinion is the most suitable pedagogy for OIM or other graduate course. Because the learning goal of the graduate course is no longer be to outstand among others in one or several particular exams but to be capable of apply the knowledge in their research work (usually with others). As a consequence, not only the competitive and individualistic learning should be put LESS stress on but also the cooperation and communication skills need to be emphasized in the graduate period. Moreover, the diverse study or think mode of each member, which is a negative drag in traditional lecture learning, can play a positive role in this procedure for there could be a chance for them to think differently and learn from each other. Besides, we all have had some successful and delightful teaching experiences of using learning by teaching pedagogy, a method of teaching in which students are made to learn material and prepare lessons to teach it to the other students.

On the basis of the above belief, Jigsaw cooperative learning (JCL), a student-centered learning method was introduced in the first run of English version OIM teaching. Jigsaw is a cooperative learning method that brings about both individual accountability and achievement of the team goals, which was first used in1971 in Austin ${ }^{4}$. This processes derive its name from the jigsaw puzzle as this process involves in putting the parts of the assignment together to form a whole picture of the assignment which is similar to the jigsaw puzzle. It is the element of "required" interdependence among students which makes this a unique learning method, and it is this interdependence that encourages the students to take an active part in their learning. In becoming a teacher of sorts, each student becomes a valuable resource for the others.

In the original Jigsaw learning technique, students are members of two groups: home group and expert group. In the heterogeneous home group, students are each assigned a different topic. Once a topic has been identified, students leave the home group and group with the other students with their assigned topic. In the new group, students learn the material together before returning to their home group. Once back in their home group, each student is accountable for teaching his or her assigned topic. As the objective of the OIM course is graduate students, who we believe had already had the ability of study independently, Jigsaw II technique ${ }^{6,7}$, (Robert Slavin's variation of Jigsaw in which members of the home group are assigned the same material, but focus on separate portions of the material, therefore each member must become an "expert" on his or her assigned portion and teach the other members of the home group,) and Reverse jigsaw ${ }^{8}$, (a variation created by Timothy Hedeen in which students in the expert groups teach the whole class rather than return to their home groups to teach the content,) was applied instead of the original Jigsaw learning method.

Base on some investigations on the Jigsaw II method and Reverse Jigsaw method, along with several experiences on pedagogy of Learning by Teaching, we designed the course plan for a class of more than fifty students. The OIM is a 10week-long course, the course schedule of OIM is shown in Table 1.

At the first class of OIM, the students were grouped as four teams while four typical interferometric measurement technology were chosen and assigned to them one by one. Each interferometric measurement technology includes several key contents and each member of a group was assigned a "piece" of the puzzle (content). The reference materials including a textbook of 883 pages were delivered to each student. Every student was free to go through the whole book but each of them has one particular chapter to be his priority task. Expanding information by researching was encouraged and the discussion could happen among the whole class. They were expected to research and consult with members till they get a full understanding about their puzzle piece and begin to be curious about the whole picture. The researching part and the discussion was designed to be off class for the sake of limited in-class hours. We supposed that they would learn from each other further developing their knowledge. Afterward everyone would be given 15 minutes to teach the whole class what they were assigned and answer the questions brought forward by the teachers and their classmates. As we wish, reporting back to their group and the whole class, they would teach their "piece" of the puzzle to their classmates. Then, they could complete the puzzle together. Through the procedure, they would achieve the course goal, i.e., understanding the principle of optical interference, being familiar with different kinds of interferometers, and be capable of using related techniques such as Zernike polynomial based wavefront fitting. 
Table 1. Course schedule of Optical Interferometric Measurement using Jigsaw II and Reverse jigsaw Cooperative Learning

\begin{tabular}{|c|c|c|c|}
\hline Week & \begin{tabular}{|c|} 
(Learning) \\
Objective
\end{tabular} & Content & $\begin{array}{c}\text { Presentation } \\
\text { Reporter }\end{array}$ \\
\hline 1 & $\begin{array}{l}\text { Introduction } \\
\qquad \& \\
\text { prerequisite } \\
\text { s review }\end{array}$ & $\begin{array}{l}\text { Introduction to OIM course: What it is about; What is the learning goal } \\
\text { and how it will be achieve; Course assessment. } \\
\text { Review of prerequisites: Maxwell equations and electromagnetic } \\
\text { waves; Theory of interference; Concept of measurement. } \\
\text { Jigsaw cooperative learning team grouping and material assignment. }\end{array}$ & Teacher \\
\hline 2 & \multirow[b]{2}{*}{$\begin{array}{l}\text { Newton, } \\
\text { Fizeau, and } \\
\text { Haidinger } \\
\text { Interferomet } \\
\quad \text { ers }\end{array}$} & $\begin{array}{l}\text { The physical principles of Newton, Fizeau, and Haidinger } \\
\text { interferometers, which are among the simplest and most powerful tools } \\
\text { available to a working optician and can be set up in an optical } \\
\text { workshop for routine testing of optical components to an accuracy of a } \\
\text { fraction of the wavelength of light. }\end{array}$ & Teacher \\
\hline 3 & & $\begin{array}{l}\text { Topics on amplitude division interferometers and their applications, } \\
\text { including several methods to distinguish concave and convex surfaces } \\
\text { with Newton interferometer; Simple Procedure for Estimating Peak } \\
\text { Error; the application of Newton interferometer about how to measure } \\
\text { the spherical radius; the structure and working principle of Fizeau } \\
\text { Interferometer; the requirements for the coherence of the light source } \\
\text { in the Fizeau interferometer; Haidinger interferometer and Haidinger } \\
\text { fringes; and so on. }\end{array}$ & $\begin{array}{l}\text { Members of Jigsaw } \\
\text { Group } 1 \\
\text { (After studying and } \\
\text { further researching on } \\
\text { his or her assigned } \\
\text { portion off class, they } \\
\text { will teach the whole } \\
\text { class the content.) }\end{array}$ \\
\hline 4 & \multirow{2}{*}{$\begin{array}{l}\text { Twyman- } \\
\text { Green } \\
\text { Interferomet } \\
\quad \text { er }\end{array}$} & $\begin{array}{l}\text { The physical principles and basically optical arrangement of Twyman- } \\
\text { Green interferometer, which is a modification of the Michelson } \\
\text { interferometer used to test optical components. }\end{array}$ & Teacher \\
\hline 5 & & $\begin{array}{l}\text { Topics on Twyman-Green Interferometer and its applications, } \\
\text { including optical path difference introduced by a beam splitter plate; } \\
\text { Required accuracy of the splitting surface; Spatial and temporal } \\
\text { coherence of Twyman-Green Interferometer; Application of Twyman- } \\
\text { Green Interferometer to test plane parallel plate of glass; and so on. }\end{array}$ & $\begin{array}{c}\text { Members of Jigsaw } \\
\text { Group } 2\end{array}$ \\
\hline 6 & \multirow{2}{*}{$\begin{array}{l}\text { Zernike } \\
\text { Polynomial } \\
\text { and } \\
\text { Wavefront } \\
\text { Fitting }\end{array}$} & $\begin{array}{l}\text { The theories on wave aberration function of optical imaging systems } \\
\text { and its description; Seidel Aberration Function and Zernike Circle } \\
\text { Polynomials. }\end{array}$ & Teacher \\
\hline 7 & & $\begin{array}{l}\text { Topics on Zernike Polynomial and Wavefront Fitting, including Power } \\
\text { Series Expansion; Zernike Circle Polynomial Expansion; Relationships } \\
\text { between Coefficients of Power-Series and Zernike-Polynomial } \\
\text { Expansions; Conversion between Seidel Aberrations and Zernike } \\
\text { Aberrations; Reconstruction of the Wavefront with Zernike } \\
\text { Polynomials; and so on. }\end{array}$ & $\begin{array}{c}\text { Members of Jigsaw } \\
\text { Group } 3\end{array}$ \\
\hline 8 & \multirow{2}{*}{$\begin{array}{l}\text { Phase } \\
\text { Shifting } \\
\text { Interferomet } \\
\text { ry }\end{array}$} & $\begin{array}{l}\text { The principle and development of phase shifting interferometry (PSI). } \\
\text { which is not a specific optical hardware configuration, but rather a data } \\
\text { collection and analysis method that can be applied to a great variety of } \\
\text { testing situations. }\end{array}$ & Teacher \\
\hline 9 & & $\begin{array}{l}\text { Topics on PSI, including Fundamental Concepts; Methods of Phase } \\
\text { Shifting; Detecting the Wavefront Phase by Temporal Method or } \\
\text { Spatial Methods; Several different algorithms and Phase Shift } \\
\text { Calibration. }\end{array}$ & $\begin{array}{c}\text { Members of Jigsaw } \\
\text { Group } 4\end{array}$ \\
\hline 10 & Summary & $\begin{array}{l}\text { To summarize and sort out the context of the course. To guide the } \\
\text { whole class to put their piece of puzzle together and complete the } \\
\text { Jigsaw. }\end{array}$ & Teacher \\
\hline
\end{tabular}


However, the first trial we made was hardly counted as success. Although at the end of the semester the test scores and course grades turned to be OK, which indicated that the knowledge had been surely delivered as it should be, the participation and engagement of the students were not active enough as we assumed. Students paid much more attention to the lecture given by the teachers than to those given by their classmates. The classroom turned to be loose during the lectures given by the students. Few students asked any question after their classmates' report. Since all the questions were from the teachers, the individual teaching report turned into an individual exam. Instead of trying to teach others their assigned part, all their presentations were designed in order to persuade the teacher that they've done their homework.

According to the survey conducted after the course, $48.83 \%$ of students spent more than 10 hours on preparing their presentation, $16.27 \%$ of them spent more than 20 hours. During their preparation, although $93.62 \%$ of those student felt that the knowledge assigned to others would be helpful to their own report, $86.36 \%$ of them decided to read the reference material by themselves and $84.09 \%$ of them turned to the Internet for help. $25.53 \%$ of the student had never discussed with others during his report preparation, while $36.17 \%$ of them would rather to discuss with the teachers and their acquaintance. The discussion (among the Jigsaw Group or Expert Group meeting) which is supposed to play an important role in JCL only happened in OIM at the rate of $38.3 \%$.

Only half students felt the pedagogy helpful to their learning and we even didn't know if those students are just trying to be nice. $68.09 \%$ of the students did agree that they learn better by preparing a teaching lecture by themselves, while $82.98 \%$ of them did not think the lectures given by their classmates were useful to their learning. The uneven quality of the students' lectures was the most frequently stated reason.

\section{WORK IN PROGRESS: ORIGINAL JIGSAW COOPERATIVE LEARNING DESIGN}

What is wrong? We have to rethink the whole OIM design and the JCL concept profoundly. After thorough analysis on all factors that might cause the frustration, we think there are two critical reasons which caused the failure.

The first one is the missing of discussion time in class. In the first run of OIM, the Jigsaw group and the Expert group meeting was supposed to be held off class for the sake of limited in-class hours. Our intension was to give every student a chance to teach other in class therefore we teachers could correct their misunderstanding if there was and they could improve their communication skills in English. What we lost sight of is that students from China are usually shy and unwilling to speak to others voluntarily. As we mentioned, the students in OIM were from 4 different specialties 3 different schools of our university, and the course was given at the first semester of their graduate student life when most of them just settle down in a new school and try to blend in every single thing. Most of those students never had the chance running into each other after class even they were grouped in one team. They didn't know each other. They would rather spend more time on their material than to call a meeting with some strangers.

The second one is that we might overrate their ability or confidence than we should do. As described before, Jigsaw II and Reverse jigsaw technique was applied in the OIM course for we believe that the graduate students had already had the ability of study independently and the confidence of teaching others. The truth is, most students did have the ability and confidence in their professional learning with mother language, but the situation is much different when English is involved. Most of student were not so familiar with the course in English version. Quite a few of them lacked of enough training of speaking and listening in English because of the limitation educational resource. Maybe they should be treated as high school students in an English course.

Based on this considerations, a course plan using original JCL is designed the OIM course, the schedule of which is shown in Table 2. In the OIM course, the students' will take a pretest on both English skills and professional prerequisites, which will be helpful to the teachers to understand the diversity of the students and will become the basis of jigsaw grouping. After the whole class are divided into several groups (Jigsaw groups), following a brief introduction on the content of a chapter (as an example, Newton, Fizeau, and Haidinger interferometers is the learning objective of Chapter 2), learning material will be assigned to the students at the beginning of each chapter, according to the information collected from the pretest. After some research on their assigned material (supposed to be finished off class), 
students meet first with other students who have the identical assignment (one from each jigsaw group), learn the material together and plan their presentation, trying to find a way to report it. Having finished working in their expert groups, the students reassemble in their jigsaw groups. Then each student come back to her or his jigsaw group and try to present a well-organized report to the group. The jigsaw group will listen to each reports and discuss through the whole material till they learn the whole picture. Then at the end of this chapter, a test covering all the learning materials which will be carried out to check if the students achieve the learning objective or not.

Table 2. Course schedule of Optical Interferometric Measurement using Jigsaw Cooperative Learning

\begin{tabular}{|c|c|c|c|}
\hline Week & $\begin{array}{l}\text { (Learning) } \\
\text { Objective }\end{array}$ & Content & Activities \\
\hline \multirow[b]{2}{*}{1} & $\begin{array}{l}\text { Introduction \& } \\
\text { prerequisites } \\
\text { review }\end{array}$ & $\begin{array}{l}\text { Introduction to OIM course; Review of } \\
\text { prerequisites. }\end{array}$ & Teacher's lecture \\
\hline & Pretest & $\begin{array}{l}\text { Background information collection of the } \\
\text { student by pretest; Jigsaw cooperative } \\
\text { learning team grouping and material } \\
\text { assignment based on the pretest. }\end{array}$ & $\begin{array}{l}\text { Pretest on both English skills and professional } \\
\text { prerequisites. }\end{array}$ \\
\hline \multirow[b]{2}{*}{2} & \multirow{4}{*}{$\begin{array}{l}\text { Newton, Fizeau, } \\
\text { and Haidinger } \\
\text { Interferometers }\end{array}$} & $\begin{array}{l}\text { The physical principles of Newton, } \\
\text { Fizeau, and Haidinger interferometers, } \\
\text { learning material assigning (Original } \\
\text { jigsaw mode or jigsaw II) }\end{array}$ & Teacher's lecture \\
\hline & & Expert group meeting discussion. & $\begin{array}{l}\text { After some research on their assigned material, } \\
\text { students meet first with other students who } \\
\text { have the identical assignment (one from each } \\
\text { jigsaw group), learn the material together and } \\
\text { plan their presentation, trying to find a way to } \\
\text { report it. }\end{array}$ \\
\hline \multirow[t]{2}{*}{3} & & Jigsaw home group meeting discussion. & $\begin{array}{l}\text { Each student come back to her or his jigsaw } \\
\text { group and try to present a well-organized } \\
\text { report to the group. The jigsaw group will } \\
\text { listen to each reports and discuss through the } \\
\text { whole material till they learn the whole } \\
\text { picture. }\end{array}$ \\
\hline & & $\begin{array}{l}\text { Chapter test on Newton, Fizeau, and } \\
\text { Haidinger Interferometers. }\end{array}$ & $\begin{array}{l}\text { A test covering all the learning materials will } \\
\text { be carried out. }\end{array}$ \\
\hline $4 / 5$ & $\begin{array}{l}\text { Twyman-Green } \\
\text { Interferometer }\end{array}$ & \multirow{3}{*}{\multicolumn{2}{|c|}{ Similar with Newton, Fizeau, and Haidinger Interferometers. }} \\
\hline $6 / 7$ & $\begin{array}{l}\text { Zernike } \\
\text { Polynomial and } \\
\text { Wavefront }\end{array}$ & & \\
\hline $7 / 8$ & $\begin{array}{l}\text { Phase Shifting } \\
\text { Interferometry }\end{array}$ & & \\
\hline 10 & Summary & $\begin{array}{l}\text { To summarize and sort out the context of } \\
\text { the course. }\end{array}$ & Teacher's lecture \\
\hline
\end{tabular}




\section{DISCUSSION AND FUTURE WORK}

The most challenging part of preparing the courses for graduate students might be the diversity background of the students. Traditional lectures do hardly satisfy or benefit all of them, which might lead to inactive in the class, especially when the courses are professionally concentrated. The cooperative learning method which engages all students and is beneficial in facilitating relationship-building, might be an alternative solution. Out of that consideration, Jigsaw cooperative learning method was introduced in the first run of Optical Interferometric Measurement course teaching, based on the belief that the diverse study or think mode of each member, which is a negative drag in traditional lecture learning, can play a positive role in this procedure.

However, the first trial we made is hardly counted as success. After thorough analysis on all factors that might cause the frustration, a new course plan is formed detailed. In this paper, both our unsuccessful trial and the one work in progress is discussed. The later one is still ongoing. We do not believe that there is a perfect solution in education. We will keep working on the exploration.

\section{ACKNOWLEDGEMENTS}

This work was made possible by a grant from Educational and Teaching Reform Project of Beijing Institute of Technology.

\section{REFERENCES}

[1] Patricia Blosser, Using Cooperative Learning in Science Education, The science outlook: An informational bulletin from ERIC/CSMEE (1992).

[2] Johnson, D.W., R.T. Johnson, and K.A. Smith. Active learning: Cooperation in the college classroom. Edina, MN: Interaction Book Company (1991).

[3] D.W. Johnson, R.T. Johnson, K.A. Smith. Cooperative Learning Returns to College: What Evidence Is There that it Works? Change, July/August, 27-35 (1998).

[4] Jigsaw Basic, The Jigsaw Classroom, <https://www.jigsaw.org/>

[5] Logan Fiorella, Richard E. Mayer, The relative benefits of learning by teaching and teaching expectancy, Contemporary Educational Psychology, Vol. 38, Issue 4, 281-288 (2013).

[6] CHAN Kam-wing, Using 'Jigsaw II' in Teacher Education Programmes, Hong Kong Teachers' Centre Journal, Vol.3, 91-97 (2004).

[7] QIAO Mengduo and JIN Xiaoling, Jigsaw Strategy as a Cooperative Learning Technique: Focusing on the Language LearnersChinese Journal of Applied Linguistics (Bimonthly) Vol. 33 No. 4, 113-125 (2010).

[8] Timothy Hedeen, "The Reverse Jigsaw: A Process of Cooperative Learning and Discussion," Teaching Sociology 31(3):325-332, (2004). 